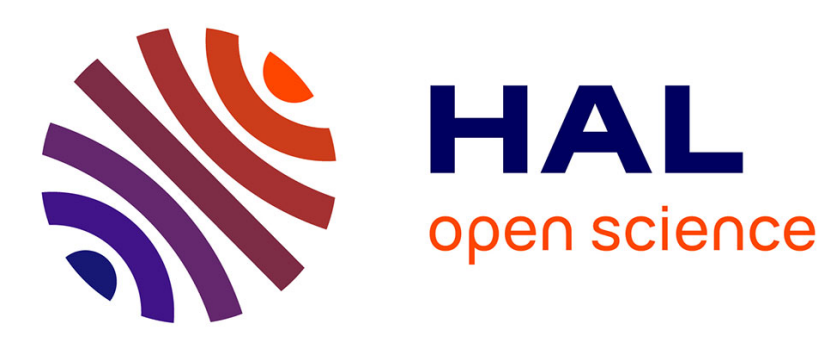

\title{
Gauss' Principle and Principle of Least Constraints for Dissipative Mechanical Systems
}

Kerim Yunt

\section{To cite this version:}

Kerim Yunt. Gauss' Principle and Principle of Least Constraints for Dissipative Mechanical Systems. 7th Vienna International Conference on Mathematical Modelling, Feb 2012, Vienne, Austria. pp.842 - 847, 10.3182/20120215-3-AT-3016.00149 . hal-01375987

\section{HAL Id: hal-01375987 \\ https://hal.science/hal-01375987}

Submitted on 5 Oct 2016

HAL is a multi-disciplinary open access archive for the deposit and dissemination of scientific research documents, whether they are published or not. The documents may come from teaching and research institutions in France or abroad, or from public or private research centers.
L'archive ouverte pluridisciplinaire HAL, est destinée au dépôt et à la diffusion de documents scientifiques de niveau recherche, publiés ou non, émanant des établissements d'enseignement et de recherche français ou étrangers, des laboratoires publics ou privés. 


\title{
Gauss' Principle and Principle of Least Constraints for Dissipative Mechanical Systems
}

\author{
Kerim Yunt* \\ *P.O Box 10708021 Zurich, Switzerland (e-mail: kerimyunt@web.de).
}

\begin{abstract}
The aim of this work is to formulate the Gauss' principle and the principle of least constraints for dissipative systems. For dynamics, where the evolution requires the determination of the accelerations of the system, it is shown that in the presence of dissipative force laws a similar principle holds, which requires the augmentation of the optimization problem of least constraints by the time rate of change of the total dissipation.
\end{abstract}

Keywords: Friction, Dissipative Systems, Principle of Gauss, Variational Inequalities, Nonsmooth Analysis

\section{INTRODUCTION}

The principle of Gauss has been published in Gauss (1829) and provides a variational criteria on admissible accelerations of bilaterally holonomically constraint mechanical systems. The principle of Gauss, that bears the the principle of least constraints, enables in addition to the above cited principles to determine the evolution of a non-impulsive mechanical process. The evolution of the mechanical system is determined by its acceleration and the principle of least constraints is about an optimization problem to determine accelerations for bilaterally constraint holonomic mechanical systems. In references Moreau (1963) and Moreau (1966), it is shown how to generalize the principle of Gauss and the principle of least constraints to finite-dimensional Lagrangian systems with frictionless unilateral constraints and the quadratic programming procedure for determining the accelerations for such mechanical systems is derived. Pozharitskii formulated in Pozharitskii (1961) the extension of the principle of least constraints for mechanical systems with planar isotropic dry friction with known normal forces by a function, he called the work of all forces applied to the system with a virtual acceleration. In Glocker (1998) a general optimization problem by putting the whole constraints in to an acceleration potential $\Psi_{\mathcal{C}}\left(\ddot{\mathrm{q}}^{+}\right)$in the form:

$$
\mathrm{f}\left(\ddot{\mathrm{q}}^{+}\right)=\frac{1}{2}\left\langle\ddot{\mathrm{q}}^{+}, \mathrm{M} \ddot{\mathrm{q}}^{+}\right\rangle-\left\langle\mathrm{h}, \ddot{\mathrm{q}}^{+}\right\rangle+\Psi_{\mathcal{C}}\left(\ddot{\mathrm{q}}^{+}\right),
$$

is proposed, which depending on the structure of the domain $\mathcal{C}$ is a strictly convex function, with $\mathrm{M}$ being the symmetric and positive-definite mass matrix and $h$ a continuous function of the generalized positions and velocities of the mechanical system but is not applicable to systems with friction. Pozharitskii considers following form of extension to the principle of least constraints in Pozharitskii (1961) for problems with tresca-type dry friction:

$$
\min _{\ddot{\mathrm{q}}^{+}} \frac{1}{2}\left\langle\ddot{\mathrm{q}}^{+}, \mathrm{M} \ddot{\mathrm{q}}^{+}\right\rangle-\left\langle\mathrm{h}, \ddot{\mathrm{q}}^{+}\right\rangle+\Psi .
$$

Pozharitskii defines the quantity:

$$
-\Psi=\sum_{\mathrm{i}=1}^{\mathrm{n}} \mathrm{Q}_{\mathrm{i}} \mathrm{a}_{\mathrm{i}}-\sum_{\mathrm{i} \in \mathrm{I}_{\mathrm{NP}}} \mu_{\mathrm{i}} \mathrm{k}_{\mathrm{n}_{\mathrm{i}}}\left|\mathrm{a}_{\mathrm{T}_{\mathrm{i}}}\right|
$$

as the work of all the forces applied to the system with a virtual acceleration, where $\mathrm{Q}$ is a generalized force and the distance function is in the Euclidean norm; $\mathrm{a}_{\mathrm{T}_{\mathrm{i}}}$ is the relative tangential acceleration at a sticking contact; $\mathrm{k}_{\mathrm{N}_{\mathrm{i}}}$ is the given normal force at a frictional. The distance of dissipation potentials are formulated in the Euclidean norm, for which norm he shows that the function is positive-definite.

The considered frictional contact law in this work, is the dry friction law of tresca type. There are two main features of dry friction. The first feature is a set $\mathcal{C}_{\mathrm{T}}$ to which frictional contact force $\gamma_{\mathrm{T}}$ belongs as admissible forces. This set depends on the magnitude of the normal contact force $\gamma_{\mathrm{N}}$. The friction coefficient $\mu$ serves as a transmissive multiplier of the normal force on the tangential direction. The second feature is about conditions which specify when sticking and sliding take place, which are related to the tangential relative contact velocity $\mathrm{v}_{\mathrm{T}}$ and acceleration $\mathrm{a}_{\mathrm{T}}$. The possibility to formulate friction models on acceleration level is shown systematically by Glocker in his monograph Glocker (2001) using nonsmooth analysis though already in Pozharitskii (1961) by Pozharitskii the spatial friction force model of tresca-type on acceleration level as well as friction acceleration potentials are used without definition, in order to extend the principle of Gauss to systems with dry friction. Though the distinction between Tresca and Coulomb type dry friction is made regularly in literature, there is no common view on how these friction laws differ from each other. In this work, Tresca type dry friction is seen as a friction law of which normal contact force is independent of future generalized accelerations at a given position and generalized velocity of the system contrary to Coulomb friction.

In this work, for mechanical systems with convex dissipation potentials (such as tresca-type of friction, signorini type normal contact law, viscous friction etc.) following 
extended problem of least constraints is proposed:

$$
\min _{\ddot{\mathrm{q}}^{+}} \frac{1}{2}\left\langle\ddot{\mathrm{q}}^{+}, \mathrm{M} \ddot{\mathrm{q}}^{+}\right\rangle-\left\langle\mathrm{h}, \ddot{\mathrm{q}}^{+}\right\rangle+\dot{\mathrm{P}}_{\mathrm{D}}
$$

where $\dot{\mathrm{P}}_{\mathrm{D}}$ is the total time rate of change of the total dissipation function. The proposed Gauss principle associated with (4) is presented as well. In Yunt (2011) the relation between the time-rate of change of the total dissipation and the dual principal of least constraints is analyzed, and it is shown, that the dual principle of least constraints is obtained by the maximization of $\dot{\mathrm{P}}_{\mathrm{D}}$ with respect to passive dissipative forces. This is achieved by the techniques of nonsmooth analysis and by using the most general definition of dissipative forces indeed more general classes of forces then only friction forces are covered. In Pozharitskii (1961) an extensive analysis for the existence and uniqueness of the solution in generalized accelerations for the minimization of his proposed augmented function is provided, which is handled in this work by the properties of convexity in nonsmooth analysis. It is shown, that the extended problem of least constraints as in (4) possesses always a minimum due to the strict convexity of the goal functional. This relatively simple argumentation on the uniqueness of the minimum is one of the advantages one derives from nonsmooth analysis. The strict convexity is of the extended problem of least constraints requires that the dissipation potentials involved on velocity and acceleration level are convex. Though dissipation potentials due to viscous friction and nonconvex dissipation potentials are not addressed in this work, viscous friction can be treated straight forward with the results of this work, whereas the consideration of nonconvex dissipation potentials which often are encountered in continuum mechanics, of course makes the optimality conditions less sharp with regards to sufficiency.

The dissipation function was introduced by Rayleigh in his classical treatise for resisting forces which are linear in the velocities. Lurie extended this idea to dissipative forces which were higher powers of the velocity in his monograph Lurie (2002). He obtained by setting the power to zero the dissipation function for the dry friction forces and by setting to one the Rayleigh dissipation function. In modern mechanics, which is equipped with potential theory and nonsmooth analysis the dissipation functions of Rayleigh and Lurie are velocity potentials and need not to be differentiable. A superpotential is a lower-semicontinuous proper convex function $\Phi(\cdot)$ such that the inclusions $\mathrm{x} \in$ $\Phi(\mathrm{y})$ and $\mathrm{y} \in \Phi^{*}(\mathrm{x})$ hold between two dual variables $\mathrm{x}$ any $\mathrm{y}$ and expresses some physical law. The second inclusion expresses the so-called inverse law and $\Phi^{*}(\mathrm{x})$ is the conjugate of $\Phi(\mathrm{y})$. In the sequel, superpotentials for normal and friction forces are introduced, which are related to dissipation functions in the classical sense. Further, these superpotential laws for frictional and normal unilateral contact are extended to the acceleration level in the sense of Glocker's work. The class of superpotentials is defined in Moreau (1968). It is known as stated in Acary and Brogliato (2008) that in the case of Tresca type friction in which the normal force does not depend on the dynamics, the friction force is modelled by using nonsmooth superpotentials which is not the case for Coulomb type dry friction. The research that has been conducted on systems with friction and contact mechanics is vast. A broad overview on finite-dimensional contact mechanics is provided in Brogliato (1999), Brogliato (2007) and Glocker (2001) and in their cited references. The excellent reviews in Stewart (2000) and Stewart (2001) provide overviews on rigid body dynamics with friction and impact.

\subsection{Preliminaries}

Let $\mathrm{f}$ be an extended-valued convex function from $\mathbb{R}^{\mathrm{n}}$ to $[0,+\infty]$ and let $\mathrm{x}$ be a point where $\mathrm{f}$ is finite. The one-sided directional derivative of $f$ at $x$ with respect to a vector $y$ is defined as:

$$
\mathrm{f}^{\prime}(\mathrm{x} ; \mathrm{y})=\lim _{\gamma \downarrow 0} \frac{\mathrm{f}(\mathrm{x}+\gamma \mathrm{y})-\mathrm{f}(\mathrm{x})}{\gamma} .
$$

If it exists $+\infty$ and $\infty$ are allowed. $A$ vector $x^{*}$ is a subgradient of a convex function $\mathrm{f}$ at a point $\mathrm{x}$ if

$$
\mathrm{f}(\mathrm{z}) \geq \mathrm{f}(\mathrm{x})+\left\langle\mathrm{x}^{*}, \mathrm{z}-\mathrm{x}\right\rangle, \quad \forall \mathrm{z}
$$

The set of all subgradients of $\mathrm{f}$ at $\mathrm{x}$ constitute the subdifferential of $\mathrm{f}$ at $\mathrm{x}$ and is denoted by $\partial \mathrm{f}(\mathrm{x})$ and is a closed convex set. Two important geometrical constructs are the tangent cone and the normal cone to a set $\mathcal{C}$. The tangent cone $\mathcal{T}_{\mathcal{C}}(\mathrm{x})$ to a set $\mathcal{C}$ at a point $\mathrm{x} \in \mathcal{C}$ is a nonempty convex closed cone and is polar to a certain nonempty closed convex cone $\mathcal{N}_{\mathcal{C}}(\mathrm{x})$ :

$$
\begin{aligned}
\mathcal{N}_{\mathcal{C}}(\mathrm{x}) & =\left\{\mathrm{z} \mid\langle\mathrm{y}, \mathrm{z}\rangle \leq 0, \quad \mathrm{y} \in \mathcal{T}_{\mathcal{C}}(\mathrm{x})\right\} \\
\mathcal{T}_{\mathcal{C}}(\mathrm{x}) & =\left\{\mathrm{y} \mid\langle\mathrm{y}, \mathrm{z}\rangle \leq 0, \quad \mathrm{z} \in \mathcal{N}_{\mathcal{C}}(\mathrm{x})\right\}
\end{aligned}
$$

The set $\mathcal{N}_{\mathcal{C}}(\mathrm{x})$ is defined to be the normal cone to $\mathcal{C}$ at $\mathrm{x}$. The function $\Psi_{\mathcal{C}}$ is the indicator function of the set $\mathcal{C}$ :

$$
\begin{aligned}
& \Psi_{\mathcal{C}}(\mathrm{x})=0, \quad \Leftrightarrow \quad \mathrm{x} \in \mathcal{C}, \\
& \Psi_{\mathcal{C}}(\mathrm{x})=+\infty, \quad \Leftrightarrow \quad \mathrm{x} \notin \mathcal{C} .
\end{aligned}
$$

An important special case in the theory of subgradients is the case, where $f$ is the indicator of a non-empty convex set $\mathcal{C}$, then its subdifferential $\partial_{\mathrm{x}} \Psi(\mathrm{x})$ is given by the normal cone at $\mathrm{x}$ to the set $\mathcal{C}, \partial_{\mathrm{x}} \Psi(\mathrm{x})=\mathcal{N}_{\mathcal{C}}(\mathrm{x})$. Let $\mathrm{f}$ be any closed convex function on $\mathbb{R}^{n}$, then the conjugate of $f(x)$ is defined as:

$$
\mathrm{f}^{*}\left(\mathrm{x}^{*}\right)=\sup _{\mathrm{x}}\left\{\left\langle\mathrm{x}, \mathrm{x}^{*}\right\rangle-\mathrm{f}(\mathrm{x})\right\}
$$

The conjugate of $\mathrm{f}^{*}$ is $\mathrm{f}$. The distance function $d_{\mathcal{C}}$, which measures the distance to a closed set is given by:

$$
d_{\mathcal{C}}(\mathrm{x})=\inf \{\|\mathrm{x}-\mathrm{s}\| \mid \mathrm{s} \in \mathcal{C}\} .
$$

The conjugate of the distance function to a convex set $d_{\mathcal{C}}^{*}$ is given by:

$$
d_{\mathcal{C}}^{*}(\mathrm{x})=\sup _{\mathrm{y}}\left\{\langle\mathrm{x}, \mathrm{y}\rangle-d_{\mathcal{C}}(\mathrm{y})\right\}=\Psi_{\mathcal{C}}^{*}(\mathrm{x})+\Psi_{\mathbb{B}}(\mathrm{x}) .
$$

The function $\Psi_{\mathcal{C}}^{*}$ is the conjugate of the indicator function of the set $\mathcal{C}$. Let $\mathrm{f}$ be a proper convex function. The domain of $\mathrm{f}$ is denoted as dom $\mathrm{f}$ and is defined as the region where $\mathrm{f}$ is finite. For $\mathrm{x} \notin \operatorname{dom} \mathrm{f}, \partial \mathrm{f}(\mathrm{x})$ is empty. For $\mathrm{x}$ in the relative interior of $\operatorname{dom} f, \partial f(x)$ is non-empty, $f^{\prime}(x ; y)$ is closed and proper as a function of $\mathrm{y}$, and

$$
\mathrm{f}^{\prime}(\mathrm{x} ; \mathrm{y})=\sup _{\mathrm{x}^{*}}\left\{\left\langle\mathrm{x}^{*}, \mathrm{y}\right\rangle \mid \mathrm{x}^{*} \in \partial \mathrm{f}(\mathrm{x})\right\}=\Psi_{\partial \mathrm{f}(\mathrm{x})}^{*}(\mathrm{y})
$$

is valid. Further, $\partial \mathrm{f}(\mathrm{x})$ is a nonempty bounded set, if and only if $x$ is an element of the interior of the domain of $f$, in which case $f^{\prime}(x ; y)$ is finite for every direction $y$. The concept of variational inequalities has been an outcome of the nonsmooth analysis, which plays an important role in 


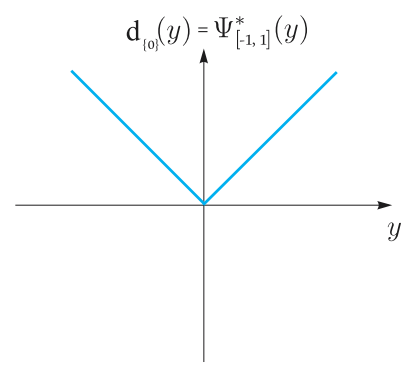

(a)

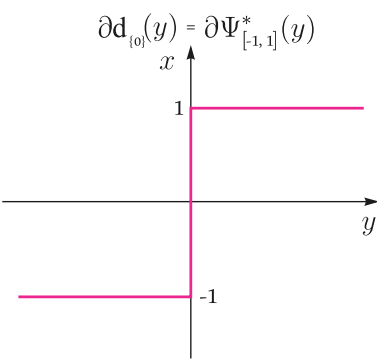

(c)

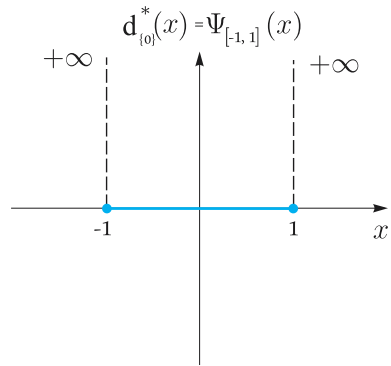

(b)

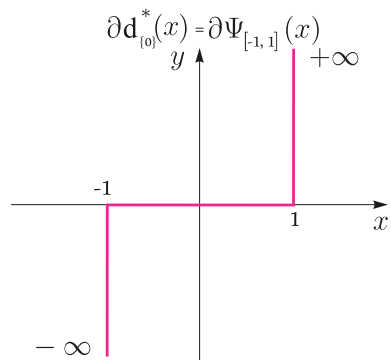

(d)
Fig. 1. In one dimension: (a) the distance function to the origin, (b) conjugate of the distance function to the origin, (c) subdifferential of the distance, (d) subdifferential of the conjugate.

applied mathematics since its introduction by Hartman and Stampacchia Hartman and Stampacchia (1966). F. H. Clarke extended the theory to non-convex functionals, that are merely lower semicontinuous and used it to derive necessary conditions for non-smooth, non-convex problems and in Clarke (1990) an overview of his contributions are given. Detailed reading on various definitions in subdifferential calculus of convex extended-valued functionals is given in Rockafellar (1970) by Rockafellar.

\section{DISSIPATIVE FORCE LAWS AND DISSIPATIVE FORCE POTENTIALS}

A force $\gamma$ is called a dissipative force, if the power of the force element $\mathrm{P}_{\gamma}(\mathrm{v})$ fulfills:

$$
\mathrm{P}_{\gamma}(\mathrm{v}):=\langle\gamma(\mathrm{v}), \mathrm{v}\rangle \leq 0 .
$$

The nonpositivity of the power of the force element is visualized best if a typical friction force law is considered. During the sticking phase, the power dissipation is zero; and is negative during the sliding phase. If there exists dissipative superpotentials in the sense of Moreau's work Moreau (1973), then there exists a scalar potential $\Phi$ which is a lower-semicontinuous convex function with $\operatorname{dom} \Phi \neq \emptyset$, such that the dissipative force is given by:

$$
\gamma \in \partial_{\mathrm{v}} \Phi(\mathrm{v}) \text {. }
$$

The conjugate of the scalar potential $\Phi^{*}$ relates the force and the velocity in the following form:

$$
\mathrm{v} \in \partial_{\gamma} \Phi^{*}(\gamma)
$$

Let $\mathrm{q}, \dot{\mathrm{q}}, \ddot{\mathrm{q}}$ represent the position, velocity and acceleration in the generalized coordinates of the basic configuration of a finite-dimensional Lagrangian system with n maximal degrees of freedom (DOF), respectively. A contact between two rigid bodies is seen as a point-to-point contact. Let the scalar function $\mathrm{d}_{\mathrm{N}}(\mathrm{q})$ denote the shortest normal distance between two rigid bodies in the system as depicted in figure (3). The normal contact distances are always nonnegative due to the impenetrability at rigid body contacts. Further, there exist no attracting forces at the rigid body contacts. A contact is closed, if the normal contact distance $d_{N}$, normal contact velocity $\mathrm{v}_{\mathrm{N}}$ are both zero. The relation between these kinematic entities is given as follows:

$$
\dot{\mathrm{d}}_{\mathrm{N}}=\mathrm{v}_{\mathrm{N}}=\frac{\partial \mathrm{d}_{\mathrm{N}}}{\partial \mathrm{q}} \dot{\mathrm{q}}=\mathrm{J}_{\mathrm{N}}^{\mathrm{T}} \dot{\mathrm{q}} \text {. }
$$

The normal contact acceleration is analogously given by:

$$
\dot{\mathrm{v}}_{\mathrm{N}}=\mathrm{J}_{\mathrm{N}}^{\mathrm{T}} \ddot{\mathrm{q}}+\dot{\mathrm{J}}_{\mathrm{N}}^{\mathrm{T}} \dot{\mathrm{q}}=\mathrm{J}_{\mathrm{N}}^{\mathrm{T}} \ddot{\mathrm{q}}+\mathrm{p}_{\mathrm{N}} \text {. }
$$

The tangential relative contact velocity and acceleration are defined by:

$$
\mathrm{v}_{\mathrm{T}}=\mathrm{J}_{\mathrm{T}}^{\mathrm{T}} \dot{\mathrm{q}} \quad \text { and } \quad \dot{\mathrm{v}}_{\mathrm{T}}^{+}=\mathrm{J}_{\mathrm{T}}^{\mathrm{T}} \ddot{\mathrm{q}}+\dot{\mathrm{J}}_{\mathrm{T}}^{\mathrm{T}} \dot{\mathrm{q}}=\mathrm{J}_{\mathrm{T}}^{\mathrm{T}} \ddot{\mathrm{q}}+\mathrm{p}_{\mathrm{T}},
$$

respectively. The friction force exists on a disk with normal contact force dependent radius in $\mathbb{R}^{2}$. The friction force is limited to the following set:

$$
\gamma_{\mathrm{T}} \in-\mu \gamma_{\mathrm{N}} \mathbb{B}_{2}=\mathcal{C}_{\mathrm{T}},
$$

where $\mathbb{B}_{2}$ is the unit ball $\mathbb{R}^{2}$. Let for a given positive $\gamma_{\mathrm{N}}$ and $\mu, \mathrm{f}_{\mathrm{T}}$ be defined as:

$$
\mathrm{f}_{\mathrm{T}}=-\frac{\gamma_{\mathrm{T}}}{\mu \gamma_{\mathrm{N}}}
$$

It is obvious that $\mathrm{f}_{\mathrm{T}} \in \mathbb{B}_{2}$. If at any instant the dissipativity condition $\left\langle\gamma_{\mathrm{T}}, \mathrm{v}_{\mathrm{T}}\right\rangle \leq 0$ is valid, then one has by the definition of the normal cone the following inclusion:

$$
\mathrm{v}_{\mathrm{T}} \in \mathcal{N}_{\mathbb{B}_{2}}\left(\mathrm{f}_{\mathrm{T}}\right) \text {. }
$$

The subdifferential of the indicator function of a convex set is given by its normal cone at that location. By making use of this relation, one has:

$$
\mathrm{v}_{\mathrm{T}} \in \partial \Psi_{\mathbb{B}_{2}}\left(\mathrm{f}_{\mathrm{T}}\right) .
$$

According to relation (13) we have $\Psi_{\mathbb{B}_{2}}^{*}\left(\mathrm{v}_{\mathrm{T}}\right)=\mathrm{d}_{\{0\}}\left(\mathrm{v}_{\mathrm{T}}\right)$, which is the distance function of the tangential velocity to the origin. By this relation the following is valid:

$$
-\gamma_{\mathrm{T}} \in \mu \gamma_{\mathrm{N}} \partial \mathrm{d}_{\{0\}}\left(\mathrm{v}_{\mathrm{T}}\right) \text {. }
$$

The function $\mu \gamma_{\mathrm{N}} \mathrm{d}_{\{0\}}\left(\mathrm{v}_{\mathrm{T}}\right)$ is a nonsmooth function, which is the dissipation function for spatial friction in this work. It encompasses also the behaviour of the frictional contact at sticking which is enabled by its nonsmoothness at the origin. However, it serves as a superpotential in the sense of Moreau only in case of dry friction where the normal force is known. The relation between the kinematics in normal direction and normal contact force $\gamma_{\mathrm{N}}$ for a single contact is expressed as Signorini type complementarity relations:

$$
\begin{array}{r}
\mathrm{d}_{\mathrm{N}}>0 \Rightarrow \gamma_{\mathrm{N}}=0, \\
\mathrm{~d}_{\mathrm{N}}=0, \quad \mathrm{v}_{\mathrm{N}}>0 \Rightarrow \gamma_{\mathrm{N}}=0, \\
\mathrm{~d}_{\mathrm{N}}=0, \quad \mathrm{v}_{\mathrm{N}}=0, \dot{\mathrm{v}}_{\mathrm{N}}=0 \Rightarrow \gamma_{\mathrm{N}} \geq 0, \\
\mathrm{~d}_{\mathrm{N}}=0, \quad \mathrm{v}_{\mathrm{N}}=0, \dot{\mathrm{v}}_{\mathrm{N}}>0 \Rightarrow \gamma_{\mathrm{N}}=0 .
\end{array}
$$

It is easily verified that the Signorini type unilateral contact law defines a dissipative force law if one notices that $\left\langle\mathrm{v}_{\mathrm{N}},-\gamma_{\mathrm{N}}\right\rangle=0$ is valid. The dissipation condition requires $\left\langle\mathrm{v}_{\mathrm{N}}, \gamma_{\mathrm{N}}\right\rangle \leq 0$ to hold, which is moulded into a normal cone inclusions:

$$
\mathrm{v}_{\mathrm{N}} \in \mathcal{N}_{\mathbb{R}_{0}^{-}}\left(-\gamma_{\mathrm{N}}\right), \quad-\gamma_{\mathrm{N}} \in \mathcal{N}_{\mathbb{R}_{0}^{+}}\left(\mathrm{v}_{\mathrm{N}}\right) .
$$

The velocity superpotential of the normal contact force law is:

$$
\Phi\left(\mathrm{v}_{\mathrm{N}}\right)=\Psi_{\mathbb{R}_{0}^{+}}\left(\mathrm{v}_{\mathrm{N}}\right) .
$$




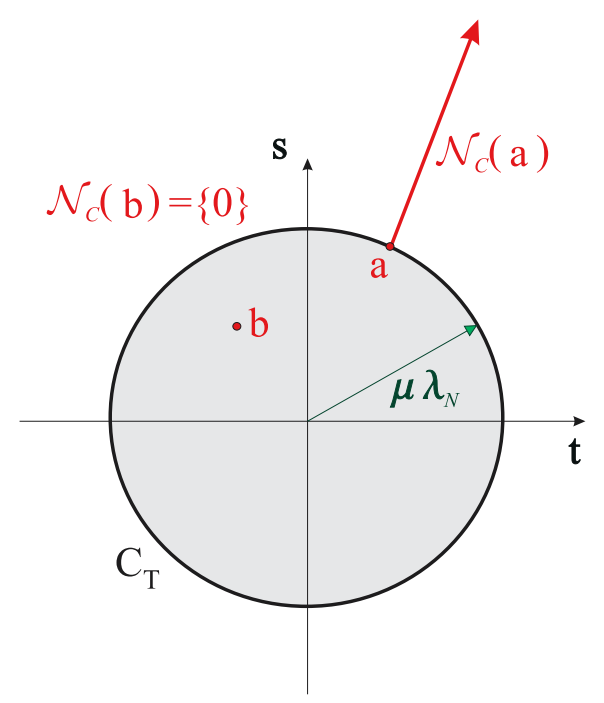

Fig. 2. The spatial frictional disc $\mathcal{C}_{\mathrm{T}}\left(\gamma_{\mathrm{N}}\right)$ with normal force dependent radius and various normal cones (red).

This definition of dissipativity encompasses the normal force potential formulated on velocity level, which is a force law with exactly zero dissipated power.

The nonsmooth dissipation potentials capture the behaviour of the dissipative force laws also at the origin. Any relative velocity is approximated by the truncated Taylor series for small enough $\tau$ :

$$
\mathrm{v}(\mathrm{t}+\tau)=\mathrm{v}(\mathrm{t})+\dot{\mathrm{v}}(\mathrm{t}) \tau .
$$

The generalized directional derivative of the function $\mathrm{d}_{\{0\}}\left(\mathrm{v}_{\mathrm{T}}\right)$ at the origin in the direction $\dot{\mathrm{v}}_{\mathrm{T}}^{+}(\mathrm{t})$ is given by:

$$
\begin{aligned}
& \mathrm{d}_{\{0\}}^{\prime}\left(\mathrm{v}_{\mathrm{T}} ; \dot{\mathrm{v}}_{\mathrm{T}}^{+}\right)= \\
& \limsup _{\substack{\mathrm{v}_{\mathrm{T}} \rightarrow 0 \\
\tau \downarrow 0^{+}}} \frac{\mathrm{d}_{\{0\}}\left(\mathrm{v}_{\mathrm{T}}+\dot{\mathrm{v}}_{\mathrm{T}}^{+} \tau\right)-\mathrm{d}_{\{0\}}\left(\mathrm{v}_{\mathrm{T}}\right)}{\left\|\dot{\mathrm{v}}_{\mathrm{T}}^{+} \tau\right\|}=1 .
\end{aligned}
$$

This result shows that locally around $\mathrm{v}_{\mathrm{T}}=0$, one has $\mathrm{d}_{\{0\}}\left(\mathrm{v}_{\mathrm{T}}\right)=\mathrm{d}_{\{0\}}\left(\dot{\mathrm{v}}_{\mathrm{T}}^{+}\right)$. The upper subderivative of the normal force velocity potential $\Psi_{\mathbb{R}_{0}^{+}}\left(\mathrm{v}_{\mathrm{N}}\right)$ at the origin in any direction $\dot{\mathrm{v}}_{\mathrm{N}}(\mathrm{t})$ is:

$$
\Psi_{\mathbb{R}_{0}^{+}}^{\prime}\left(\mathrm{v}_{\mathrm{N}}=0 ; \dot{\mathrm{v}}_{\mathrm{N}}^{+}\right)=\left\{\begin{array}{l}
\infty, \text { if } \dot{\mathrm{v}}_{\mathrm{N}}^{+} \notin \mathcal{T}_{\mathbb{R}_{0}^{+}}(0), \\
0, \text { if } \dot{\mathrm{v}}_{\mathrm{N}}^{+} \in \mathcal{T}_{\mathbb{R}_{0}^{+}}(0)
\end{array}\right.
$$

The tangent cone $\mathcal{T}_{\mathbb{R}_{0}^{+}}$at 0 is given by $\mathbb{R}_{0}^{+}$. So the upper subderivative becomes:

$$
\Psi_{\mathbb{R}_{0}^{+}}^{\prime}\left(\mathrm{v}_{\mathrm{N}}=0 ; \dot{\mathrm{v}}_{\mathrm{N}}^{+}\right)=\Psi_{\mathbb{R}_{0}^{+}}\left(\dot{\mathrm{v}}_{\mathrm{N}}^{+}\right)
$$

The following relations hold based on the definition of the one-sided directional derivative:

$$
\begin{aligned}
& \Psi_{\mathbb{R}_{0}^{+}}^{\prime}\left(0 ; \dot{\mathrm{v}}_{\mathrm{N}}^{+}\right)= \\
& \Psi_{\mathbb{R}_{0}^{+}}\left(\dot{\mathrm{v}}_{\mathrm{N}}^{+}\right)=\sup _{\gamma_{\mathrm{N}}}\left\{-\left\langle\gamma_{\mathrm{N}}, \dot{\mathrm{v}}_{\mathrm{N}}^{+}\right\rangle,-\gamma_{\mathrm{N}} \in \mathbb{R}_{0}^{-}\right\}, \\
& \mathrm{d}_{\{0\}}^{\prime}\left(0 ; \dot{\mathrm{v}}_{\mathrm{T}}^{+}\right)= \\
& \mathrm{d}_{\{0\}}\left(\dot{\mathrm{v}}_{\mathrm{T}}^{+}\right)=\sup _{\mathrm{f}_{\mathrm{T}}}\left\{\left\langle\mathrm{f}_{\mathrm{T}}, \dot{\mathrm{v}}_{\mathrm{T}}^{+}\right\rangle, \mathrm{f}_{\mathrm{T}} \in \mathbb{B}_{2}\right\} .
\end{aligned}
$$

According to (14) the following relations hold:

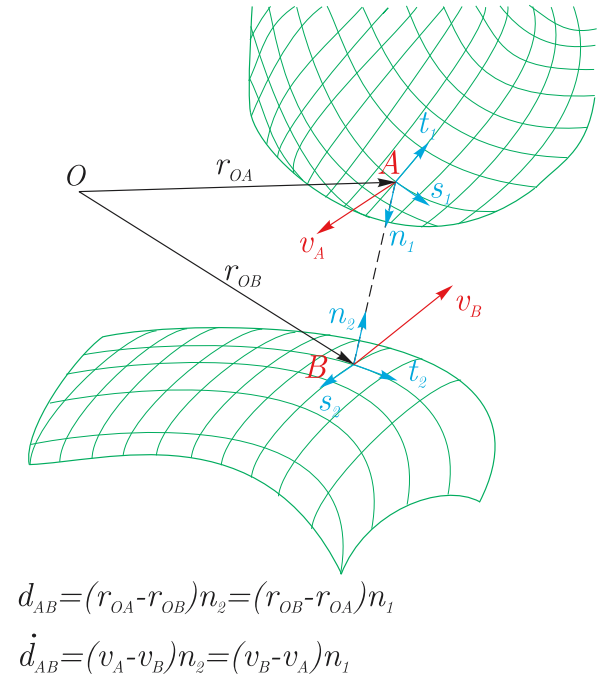

Fig. 3. The geometry of a single spatial rigid body contact between two rigid bodies.

$$
\begin{aligned}
& \Psi_{\mathbb{R}_{0}^{+}}\left(\dot{\mathrm{v}}_{\mathrm{N}}^{+}\right)= \\
& \quad \sup _{\gamma_{\mathrm{N}}}\left\{-\left\langle\gamma_{\mathrm{N}}, \dot{\mathrm{v}}_{\mathrm{N}}^{+}\right\rangle,-\gamma_{\mathrm{N}} \in \partial \Psi_{\mathbb{R}_{0}^{+}}\left(\mathrm{v}_{\mathrm{N}}^{+}\right)\right\}, \\
& \mathrm{d}_{\{0\}}\left(\dot{\mathrm{v}}_{\mathrm{T}}^{+}\right)= \\
& \quad \sup _{\mathrm{f}_{\mathrm{T}}}\left\{\left\langle\mathrm{f}_{\mathrm{T}}, \dot{\mathrm{v}}_{\mathrm{T}}^{+}\right\rangle, \mathrm{f}_{\mathrm{T}} \in \partial \mathrm{d}_{\{0\}}\left(\mathrm{v}_{\mathrm{T}}^{+}\right)\right\} .
\end{aligned}
$$

Due to conjugation following equalities hold for $\mathrm{v}_{\mathrm{N}}=0$ and $\mathrm{v}_{\mathrm{T}}=0$ :

$$
\begin{aligned}
& \Psi_{\mathbb{R}_{0}^{+}}\left(\dot{\mathrm{v}}_{\mathrm{N}}^{+}\right)+\Psi_{\mathbb{R}_{0}^{-}}\left(-\gamma_{\mathrm{N}}\right)=-\left\langle\dot{\mathrm{v}}_{\mathrm{N}}^{+}, \gamma_{\mathrm{N}}\right\rangle, \\
& \mathrm{d}_{\{0\}}\left(\dot{\mathrm{v}}_{\mathrm{T}}^{+}\right)+\Psi_{\mathbb{R}_{0}^{-}}\left(-\gamma_{\mathrm{T}}\right)=-\left\langle\dot{\mathrm{v}}_{\mathrm{T}}^{+}, \mathrm{f}_{\mathrm{T}}\right\rangle .
\end{aligned}
$$

The time-rate of change of the friction force dissipation function except at the origin is:

$$
\dot{\mathrm{d}}_{\{0\}}\left(\mathrm{v}_{\mathrm{T}}\right)=\left\langle\frac{\mathrm{v}_{\mathrm{T}}}{\left|\mathrm{v}_{\mathrm{T}}\right|}, \mathrm{a}_{\mathrm{T}}\right\rangle=\left\langle-\frac{\gamma_{\mathrm{T}}\left(\mathrm{v}_{\mathrm{T}}\right)}{\mu \gamma_{\mathrm{N}}}, \mathrm{a}_{\mathrm{T}}\right\rangle .
$$

At the origin it is given by:

$$
\left.\frac{\mathrm{d}}{\mathrm{dt}}\left(\mu \gamma_{\mathrm{N}} \mathrm{d}_{\{0\}}\left(\mathrm{v}_{\mathrm{T}}\right)\right)\right|_{\mathrm{v}_{\mathrm{T}}=0}=\mu \gamma_{\mathrm{N}} \mathrm{d}_{\{0\}}\left(\mathrm{a}_{\mathrm{T}}\right) \text {. }
$$

The derivative of the normal contact velocity potential with respect to time is:

$$
\dot{\Psi}_{\mathbb{R}_{0}^{+}}\left(\mathrm{v}_{\mathrm{N}}\right)=\left\langle\mathrm{a}_{\mathrm{N}},-\gamma_{\mathrm{N}}\right\rangle, \quad-\gamma_{\mathrm{N}} \in \partial \Psi_{\mathbb{R}_{0}^{+}}\left(\mathrm{v}_{\mathrm{N}}\right) .
$$

\section{MATHEMATICAL MODELLING OF MECHANICS}

In order to formulate the index sets that account for the force laws properly, the following index sets are introduced:

$$
\mathrm{I}_{\mathrm{S}}=\left\{\mathrm{i} \mid \mathrm{d}_{\mathrm{N}_{\mathrm{i}}}=0\right\}, \quad \mathrm{I}_{\mathrm{N}}=\left\{\mathrm{i} \mid \mathrm{d}_{\mathrm{N}_{\mathrm{i}}}=0, \quad \mathrm{v}_{\mathrm{N}_{\mathrm{i}}}=0\right\} .
$$

The set $\mathrm{I}_{\mathrm{S}}$ denotes the set of all contacts that are closed on position level of the system. The set $\mathrm{I}_{\mathrm{N}}$, with a number of $\mathrm{k}$ elements, denotes the set of all contacts at which normal contact velocity and normal contact distance equal to zero. In this case the active dissipative friction forces are the contacts at which sliding takes place. The set of passive friction forces consist of those which stick $\left(\mathrm{v}_{\mathrm{T}}=0\right)$. The index sets of sliding contacts and sticking 
contacts are named $\mathrm{I}_{\mathrm{NA}}$ and $\mathrm{I}_{\mathrm{NP}}$, respectively. The normal contact force is passive if the associated normal contact velocity is zero. The sticking and the sliding contact forces are incorporated by the appropriate generalized force directions in the equations of motion, which are the columns of the linear operators $\mathrm{J}_{\mathrm{TA}}$ and $\mathrm{J}_{\mathrm{TP}}$, respectively. For a finite-dimensional Lagrangian system with $n$ degrees of freedom and $l$ active sliding contacts and $m$ passive sticking contacts, which have spatial friction, $\mathrm{J}_{\mathrm{TA}}(\mathrm{q})$ is a $n$ by $2 \mathrm{l}$ and $J_{\mathrm{TP}}(\mathrm{q})$ is a $\mathrm{n}$ by $2 \mathrm{~m}$ linear operators of generalized friction force directions. The linear operator $\mathrm{J}_{\mathrm{N}}(\mathrm{q})$ is a $\mathrm{n}$ by $\mathrm{k}$ linear operator of generalized normal force directions. Given this setting the differential inclusion of a mechanical system with tresca-type friction at the contacts is stated as:

$$
\begin{aligned}
& \mathrm{M} \ddot{\mathrm{q}}-\mathrm{h}-\mathrm{J}_{\mathrm{TA}} \gamma_{\mathrm{TA}}-\mathrm{J}_{\mathrm{TP}} \gamma_{\mathrm{TP}}-\mathrm{J}_{\mathrm{N}} \gamma_{\mathrm{N}}=0, \\
& -\gamma_{\mathrm{N}_{\mathrm{i}}} \in \partial \Psi_{\mathbb{R}_{0}^{+}}\left(\mathrm{a}_{\mathrm{N}_{\mathrm{i}}}\right), \quad \forall \mathrm{i} \in \mathrm{I}_{\mathrm{N}}, \\
& \gamma_{\mathrm{TA}_{\mathrm{i}}}=-\mu_{\mathrm{i}} \mathrm{k}_{\mathrm{N}_{\mathrm{i}}} \frac{\mathrm{v}_{\mathrm{T}_{\mathrm{i}}}}{\left\|\mathrm{v}_{\mathrm{T}_{\mathrm{i}}}\right\|}, \forall \mathrm{i} \in \mathrm{I}_{\mathrm{NA}}, \\
& -\gamma_{\mathrm{TP}_{\mathrm{i}}} \in \mu_{\mathrm{i}} \mathrm{k}_{\mathrm{N}_{\mathrm{i}}} \partial_{\mathrm{a}_{\mathrm{TP}_{\mathrm{i}}}} \mathrm{d}_{\{0\}}\left(\mathrm{a}_{\mathrm{TP}_{\mathrm{i}}}\right), \forall \mathrm{i} \in \mathrm{I}_{\mathrm{NP}} .
\end{aligned}
$$

$\mathrm{M}(\mathrm{q})$ is the symmetric positive-definite (PD) mass matrix and $\mathrm{h}(\mathrm{q}, \dot{\mathrm{q}})$ represents the vector of gyroscopic, centripetal and coriolis forces and encompasses also smooth force elements such as springs and dampers. Here $\mathrm{k}_{\mathrm{N}_{\mathrm{i}}}$ are the normal contact forces at the tresca-type frictional contacts for which the normal force is not dependent on the future generalized accelerations at a given state.

Having set the stage, the total dissipation function is given as:

$$
\mathrm{P}_{\mathrm{D}}\left(\mathrm{v}_{\mathrm{T}}, \mathrm{v}_{\mathrm{N}}\right)=\sum_{\mathrm{i} \in \mathrm{I}_{\mathrm{S}}} \Psi_{\mathbb{R}_{0}^{+}}\left(\mathrm{v}_{\mathrm{n}_{\mathrm{i}}}\right)+\sum_{\mathrm{i} \in \mathrm{I}_{\mathrm{NP}} \cup \mathrm{I}_{\mathrm{NA}}} \mu_{\mathrm{i}} \mathrm{k}_{\mathrm{n}_{\mathrm{i}}} \mathrm{d}_{\{0\}}\left(\mathrm{v}_{\mathrm{T}_{\mathrm{i}}}\right) .
$$

The time rate of change $\dot{\mathrm{P}}_{\mathrm{D}}$ is evaluated by making use of (42), (43), (44) as follows:

$$
\begin{aligned}
& \dot{\mathrm{P}}_{\mathrm{D}}=\sum_{\mathrm{i} \in \mathrm{I}_{\mathrm{N}}} \Psi_{\mathbb{R}_{0}^{+}}\left(\mathrm{a}_{\mathrm{n}_{\mathrm{i}}}\right) \\
& +\sum_{\mathrm{i} \in \mathrm{I}_{\mathrm{NP}}} \mu_{\mathrm{i}} \mathrm{k}_{\mathrm{n}_{\mathrm{i}}} \mathrm{d}_{\{0\}}\left(\mathrm{a}_{\mathrm{T}_{\mathrm{i}}}\right)-\sum_{\mathrm{i} \in \mathrm{I}_{\mathrm{NA}}}\left\langle\gamma_{\mathrm{T}_{\mathrm{i}}}\left(\mathrm{v}_{\mathrm{T}_{\mathrm{i}}}\right), \mathrm{a}_{\mathrm{T}_{\mathrm{i}}}\right\rangle .
\end{aligned}
$$

\section{PRINCIPLE OF LEAST CONSTRAINTS FOR DISSIPATIVE MECHANICAL SYSTEMS}

The well-known principle of maximal dissipation does not specify what dissipative forces shall do if the relative velocity vanishes at given generalized velocity and position, though this maximization of the dissipativity happens recurrently at every position and velocity of the mechanical system. On the other side, the dissipative forces, influence the evolution of the system by determining the acceleration $\ddot{q}$ in general. The generalized acceleration of the mechanical system is related to dissipative forces by the set of relations given by (45) to (48) for a given state specified by the position $\mathrm{q}$ and the generalized velocity $\dot{\mathrm{q}}$. Any optimization in the passive dissipative forces can thereby related to a search of the generalized acceleration in the next moment. Following extended problem of least constraints is proposed in this work:

$$
\min _{\ddot{\mathrm{q}}^{+}} \frac{1}{2}\left\langle\ddot{\mathrm{q}}^{+}, \mathrm{M} \ddot{\mathrm{q}}^{+}\right\rangle-\left\langle\mathrm{h}, \ddot{\mathrm{q}}^{+}\right\rangle+\dot{\mathrm{P}}_{\mathrm{D}} \text {. }
$$

The unconstrained minimization problem (51) is the principle of least constraint for the considered type of mechanical systems. Here $\ddot{\mathrm{q}}^{+}$is the right-continuous generalized acceleration, which is the acceleration in the imminent future. The necessary condition of optimality of (51) takes following form:

$$
-\left(\mathrm{M}(\mathrm{q}) \ddot{\mathrm{q}}^{+}-\mathrm{h}(\mathrm{q}, \dot{\mathrm{q}})\right) \in \partial_{\ddot{\mathrm{q}}}+\dot{\mathrm{P}}_{\mathrm{D}}
$$

The directional derivative of the unconstrained goal functional requires for a minimum following condition:

$$
\dot{\mathrm{P}}_{\mathrm{D}}^{\prime}\left(\cdot ; \tilde{\ddot{\mathrm{q}}}^{+}-\ddot{\mathrm{q}}^{+}\right)+\left\langle\mathrm{M} \ddot{\mathrm{q}}^{+}-\mathrm{h}, \tilde{\ddot{\mathrm{q}}}^{+}-\ddot{\mathrm{q}}^{+}\right\rangle \geq 0 .
$$

The vector $\tilde{\ddot{q}}^{+}$denotes the arbitrary unconstrained virtual future accelerations. The requirement of (53) represents the Gauss Principle for dissipative mechanical systems with convex dissipation potentials. The dependence of the relative accelerations as in $\dot{\mathrm{P}}_{\mathrm{D}}^{\prime}$ on $\ddot{\mathrm{q}}^{+}$are given by relations (18) and (19). The directional derivative of $\dot{\mathrm{P}}_{\mathrm{D}}^{\prime}$ becomes by making use of (18) and (19):

$\dot{\mathrm{P}}_{\mathrm{D}}^{\prime}\left(\cdot ; \tilde{\ddot{\mathrm{q}}}^{+}-\ddot{\mathrm{q}}^{+}\right)=\left\langle-\mathrm{J}_{\mathrm{N}} \gamma_{\mathrm{N}}-\mathrm{J}_{\mathrm{TP}} \gamma_{\mathrm{TP}}-\mathrm{J}_{\mathrm{TA}} \gamma_{\mathrm{TA}}, \tilde{\ddot{\mathrm{q}}}^{+}-\ddot{\mathrm{q}}^{+}\right\rangle$.

By combinining (53) and (54) following optimality condition is obtained:

$$
\left\langle\mathrm{M} \ddot{\mathrm{q}}^{+}-\mathrm{h}-\mathrm{J}_{\mathrm{N}} \gamma_{\mathrm{N}}-\mathrm{J}_{\mathrm{TP}} \gamma_{\mathrm{TP}}-\mathrm{J}_{\mathrm{TA}} \gamma_{\mathrm{TA}}, \tilde{\ddot{\mathrm{q}}}^{+}-\ddot{\mathrm{q}}^{+}\right\rangle \geq 0,
$$

which for arbitrary unconstrained virtual future accelerations $\tilde{\ddot{q}}^{+}$is only fulfilled, if the equations of motion given by (45) hold.

\section{DISCUSSION AND CONCLUSION}

In this work it is proven mathematically, that the principle of least constraints for mechanical systems with convex dissipation potentials is given by (51). The principle of Gauss for mechanical systems with tresca type of dry friction is shown to be related to the time-rate of change of the total dissipation. The new principle can be extended to include general dissipative force laws, which derive from convex potentials. This relation is accomplished by making use of the most general definition of dissipative forces and applying the methods and techniques of nonsmooth analysis.

\section{REFERENCES}

Acary, V. and Brogliato, B. (2008). Numerical Methods for Nonsmooth Dynamical Systems-Applications in Mechanics and Electronics, volume 35 of Lecture Notes in Applied and Computational Mechanics. Springer.

Brogliato, B. (1999). Nonsmooth Mechanics: Models, Dynamics and Control. Communications and Control Engineering. Springer, 2nd edition.

Brogliato, B. (2007). Dissipative Systems Analysis and Control: Theory and Applications. Communications and Control Engineering. Springer, 2nd edition.

Clarke, F. (1990). Optimisation and Nonsmooth Analysis. Number 5 in Classics in Applied Mathematics. SIAM.

Gauss, C.F. (1829). Über ein neues allgemeines grundgesetz der mechanik. J. Reine Angew. Math., 4, 232-235. 
Glocker, C. (1998). The principles of d'alembert, jourdain, and gauss in nonsmooth dynamics part 1: Sclerenomic multibody systems. Zeitschrift für Angewandte Mechanik und Mathematik, 78(1), 21-37.

Glocker, C. (2001). Set-Valued Force Laws - Dynamics of Non-Smooth Systems, volume 1 of Lecture Notes in Applied Mechanics. Springer Verlag.

Hartman, P. and Stampacchia, G. (1966). On some nonlinear elliptic differential equations. Acta Math., $115(1), 153-188$.

Lurie, A.I. (2002). Analytical Mechanics. Springer.

Moreau, J.J. (1963). Les liaisons unilatérales et le principe de gauss. Ibid., 256, 871-874.

Moreau, J.J. (1966). Quadratic programming in mechanics: Dynamics of one-sided constraints. J. SIAM. Control, 4(1), 153-158.

Moreau, J.J. (1968). La notion de sur-potentiel et les liasions unilatérales en élastostatique. C. R. Acad. Sci. Paris, A271, 954-957.

Moreau, J.J. (1973). New variational techniques in Mathematical Physics, chapter On unilateral constraints, friction and plasticity, 172-322.

Pozharitskii, G.K. (1961). Extension of the principle of gauss to systems with dry (coulomb) friction. Journal of Appl. Math. and Mech., 25(3), 586-607.

Rockafellar, R.T. (1970). Convex Analysis. Princeton Landmarks in Mathematics and Physics. Princeton University Press.

Stewart, D.E. (2000). Rigid-body dynamics with friction and impact. SIAM Review, 42(1), 3-39.

Stewart, D.E. (2001). Finite-dimensional contact mechanics. Phil. Trans. R. Soc. Lond. A, 359, 2467-2482.

Yunt, K. (2011). On the relation between the dual principle of least constraints and the principle of maximal dissipation. In Proc. of the rth WSEAS Int. Conf. on Applied and Theoretical Mechanics, 75-80. Montreux, Switzerland. 